\title{
Do Symptoms and Serum Calcium Levels Affect the Results of Surgical Treatment of Primary Hyperparathyroidism?
}

\author{
QingAn Yu, KunPeng Liu, DaKun Ma, ChangMing Xie, YaoHua Wu, \\ WenJie Dai $(\mathbb{D}$, and HongChi Jiang $(\mathbb{D})$ \\ Department of Thyroid Surgery, The First Affiliated Hospital Harbin Medical University, Harbin 150001, China \\ Correspondence should be addressed to WenJie Dai; wenjiedai@126.com and HongChi Jiang; jianghc2013@163.com
}

Received 31 March 2019; Revised 5 June 2019; Accepted 12 June 2019; Published 1 July 2019

Academic Editor: Raffaele Serra

Copyright (c) 2019 QingAn Yu et al. This is an open access article distributed under the Creative Commons Attribution License, which permits unrestricted use, distribution, and reproduction in any medium, provided the original work is properly cited.

\begin{abstract}
Introduction. The purpose of this study was to investigate the difference in surgical outcomes between symptomatic and asymptomatic patients with primary hyperparathyroidism (PHPT) and between patients with high serum calcium and those with normal blood calcium, as well as to explore the epidemiological trend of PHPT in northern China. Methods. Clinicopathologic data of 197 patients (50 men and 147 women) with PHPT who underwent surgery at the First Affiliated Hospital of Harbin Medical University from 2008 to 2017 were analyzed. Changes in clinicopathology were compared among different subgroups of patients. Patients were categorized into subgroups based on serum calcium levels, whether or not they presented with symptoms, and admission time. Results. Of the total patients, $82.23 \%$ had hypercalcemic primary hyperparathyroidism (HCPHPT), $17.77 \%$ had normocalcemic primary hyperparathyroidism (NCPHPT), 45.18\% had symptomatic primary hyperparathyroidism (SPHPT), and $54.82 \%$ had asymptomatic primary hyperparathyroidism (ASPHPT). Seventy-seven cases of PHPT involved thyroid nodules, with 22 confirmed as papillary thyroid carcinoma, and 29 confirmed as nodular goiter. There was no significant difference in the success rate of surgery, postoperative recurrence rate, and the symptoms of temporary hypocalcemia between the HCPHPT and NCPHPT groups, and between the SPHPT and ASPHPT groups. The incidence of PHPT has increased threefold since 2013. Conclusions. Symptoms and serum calcium levels did not affect the results of surgical treatment for PHPT. The incidence of PHPT in northern China is increasing. Moreover, PHPT manifestation has shifted from the symptomatic to the asymptomatic form. Thyroid surgery should be performed in PHPT patients with thyroid nodules.
\end{abstract}

\section{Introduction}

Before the 1970s, primary hyperparathyroidism (PHPT) was considered a rare disease, and patients presented with marked hypercalcemia and bone lesions or osteitis fibrosa cystica. However, with the advent of the multifunction autoanalyzer in the 1970s, the clinical phenotype changed. PHPT has become the third major endocrine disease in western countries following diabetes and osteoporosis [1]. According to reports from western countries, the incidence of PHPT has undergone 2 peaks. The first peak occurred during 1974-1982 and was mainly due to the increased prevalence of serum calcium screenings. The second peak occurred during 20002010 and was probably due to the targeting of PHPT screening for osteoporosis patients [2-4]. Not only the incidence but also the form of PHPT is changing. PHPT is changing mainly from hypercalcemic primary hyperparathyroidism (HCPHPT) to normocalcemic primary hyperparathyroidism (NCPHPT) [5, 6] and from symptomatic hyperparathyroidism (SPHPT) to asymptomatic primary hyperparathyroidism (ASPHPT) $[7,8]$.

It is unknown whether the changes in the forms of PHPT will affect the therapeutic outcomes of PHPT. In this study, we reviewed the treatment of PHPT over the past 10 years, discussed the abovementioned problem, and analyzed the incidence and clinical characteristics of PHPT in northern China.

\section{Materials and Methods}

2.1. Study Participants. Study participants were selected from patients treated at the Department of General Surgery at the First Affiliated Hospital of Harbin Medical University 
from 2008 to 2017. Patients who met the diagnostic criteria for PHPT, underwent parathyroidectomy, and had pathologically confirmed parathyroidism were included in this study. This study was approved by the ethics committee of the First Affiliated Hospital of Harbin Medical University. Demographic and clinicopathological information was collected regarding patients' sex, age, pre-operative biochemical examination, postoperative biochemical examination, pathological findings, operative cure rate, postoperative recurrence rate, and other clinical characteristics.

HCPHPT is characterized by high serum calcium levels and elevated parathyroid hormone (PTH) [9]. The diagnostic criteria for HCPHPT were as follows: histologically proven PHPT diagnosis, hypercalcemia (calcium level $>2.6 \mathrm{mmol} / \mathrm{L}$ ) with elevated serum PTH, and hypercalcemia with no specified cause (e.g., thiazide diuretics, cancer, creatinine level $>176.8 \mathrm{mmol} / \mathrm{L}$, or lithium therapy). NCPHPT is characterized by normal serum calcium levels and continuously elevated PTH [10]. The diagnostic criteria for NCPHPT were as follows: histologically proven PHPT diagnosis; normal serum calcium (calcium level $\leq 2.6 \mathrm{mmol} / \mathrm{L}$ ) and high $\mathrm{PTH}$ levels; serum 25-hydroxyvitamin D (25[OH]D) levels above $30 \mathrm{ng} / \mathrm{mL}$; the absence of bisphosphonates, thiazide diuretics, anticonvulsants, or lithium use; glomerular filtration rate greater than $60 \mathrm{~mL} / \mathrm{min}$; and the absence of other metabolic bone diseases or gastrointestinal diseases associated with malabsorption or liver disease. SPHPT is characterized by abnormal elevated PTH levels and is associated with organspecific symptoms, including renal disease, bone disease, gastrointestinal symptoms, mental symptoms, neuromuscular symptoms, cognitive dysfunction, and cardiovascular system symptoms [11-18]. ASPHPT is characterized by elevated PTH levels in the presence or absence of hypercalcemia with no obvious clinical symptoms or target organ manifestations [19].

2.2. Evaluations and Biochemical Analysis. Patients underwent standard evaluations that included personal histories, family histories, physical examinations, auxiliary examinations, and blood and urinary biochemical tests. Total serum calcium (reference range, 2.08-2.6 $\mathrm{mmol} / \mathrm{L}$ ), phosphate $(0.96-1.62 \mathrm{mmol} / \mathrm{L})$, creatinine $(35-80 \mu \mathrm{mol} / \mathrm{L})$, albumin (34-54 g/L), and total serum alkaline phosphatase (AKP) (reference range, 40-150 IU/L) levels were measured using an autoanalyzer (Beckman Coulter, Fullerton, California). Serum calcium was corrected using the following formula: corrected calcium $(\mathrm{mg} / \mathrm{dL})=(0.8[4.0$ - patient's albumin $(\mathrm{g} / \mathrm{dL})])+$ total calcium $(\mathrm{mg} / \mathrm{dL})$. PTH level was measured using an electrochemiluminescence immunoassay (ECLIA) (reference range, $10-69 \mathrm{pg} / \mathrm{mL}$ ) on a fully automated analyzer E 601 (Roche Diagnostics GmbH, Mannheim, Germany). The serum 25(OH)D concentration was measured using an enzyme immunoassay (assay reference range, 17.88-57.6 ng/mL [44.7-144 nmol/L]; Immunodiagnostic Systems, Boldon, United Kingdom).

All patients underwent cervical ultrasonography and/or technetium-99m-sestamibi parathyroid scintigraphy. All patients underwent urinary ultrasonography and/or abdominal X-ray radiography. Bone mineral density (BMD) was determined using a dual-energy X-ray absorptiometer (Lunar Prodigy; GE Medical Systems, Madison, Wisconsin).

2.3. Study Groups. This study analyzed data from 3 sets of study groups. Based on their serum calcium levels, PHPT patients were divided into either an HCPHPT group or an NCPHPT group. PHPT patients were also divided into either an SPHPT group or an ASPHPT group based on whether they presented with symptoms or not. The clinicopathologic features and surgical results of each group were compared. Finally, according to the time of admission, patients were divided into group A for those admitted in the period 20082012 and group B for those admitted in the period 20132017. The trend of PHPT in northern China was examined by comparing groups $\mathrm{A}$ and $\mathrm{B}$.

In addition, symptoms in each group were further divided into type I and type II symptoms. Type I symptoms were classified as single or multiple symptoms, while type II symptoms were classified according to specific symptom types.

2.4. Statistical Analysis. The data were analyzed using IBM SPSS software (Version 19.0, IBM Corp., Armonk, NY). Continuous variables were expressed as means and standard deviations. For data that were normally distributed and had homogeneous variances, the t-test was used to assess differences between groups. For data that were not normally distributed or did not have homogeneous variances, the Mann-Whitney U rank sum test was used for analysis. Categorical variables and nonparametric variables were examined by chi-square test or Fisher's exact test. P-values $<0.05$ were considered statistically significant.

\section{Results}

3.1. Overall Clinicopathologic Data. A total of 222 cases of PHPT were included, of which 23 cases were excluded because of refusal to undergo surgery, and 2 cases were excluded due to radiofrequency ablation without pathological data (Figure 1). Finally, 197 cases (50 men and 147 women) were included (Figure 1). The average age was 49 years (interquartile range: 43-57) (Table 1). Of the total patients, $162(82.23 \%)$ presented with HCPHPT, and $89(45.18 \%)$ presented with SPHPT. In addition, $161(81.73 \%)$ patients had parathyroid adenoma, $30(15.23 \%)$ had hyperplasia, $2(1.02 \%)$ had carcinoma, and 4 (2.03\%) had adenoma concurrent with hyperplasia. Among the patients with parathyroid adenoma, single adenoma accounted for $96.27 \%$ of cases, and among the patients with parathyroid hyperplasia, single parathyroid hyperplasia accounted for $66.67 \%$ of cases. Seventy-seven (39.09\%) patients had concurrent thyroid nodules, of which 51 patients underwent thyroidectomy and parathyroidectomy simultaneously. Of the 51 patients with simultaneous thyroidectomy, 22 had papillary thyroid carcinoma, and 29 had a nodular goiter. The cure rate of parathyroidectomies was $96.45 \%$. Seven cases were unsuccessful, with 4 cases having ectopic parathyroid adenoma; 1 case had multiple parathyroid 
TABLE 1: Clinicopathological data of all patients.

\begin{tabular}{lc}
\hline Index & Patients (n=197) \\
\hline Age, y (IQR) & $49(43-57)$ \\
Female & $147(74.62 \%)$ \\
Male & $50(25.38 \%)$ \\
HCPHPT & $82.23 \%(162 / 197)$ \\
NCPHPT & $17.77 \%(35 / 197)$ \\
SPHPT & $45.18 \%(89 / 197)$ \\
ASPHPT & $54.82 \%(108 / 197)$ \\
Parathyroid adenoma & $81.73 \%(161 / 197)$ \\
Parathyroid hyperplasia & $15.23 \%(30 / 197)$ \\
Parathyroid carcinoma & $1.02 \%(2 / 197)$ \\
Parathyroid adenoma with hyperplasia & $2.03 \%(4 / 197)$ \\
PHPT with thyroid nodules & $39.09 \%(77 / 197)$ \\
$\quad$ Papillary thyroid carcinoma & $43.14 \%(22 / 51)$ \\
$\quad$ Nodular goiter & $56.86 \%(29 / 51)$ \\
Cure rate of PHPT & $96.45 \%(190 / 197)$ \\
Recurrence rate of PHPT & $1.52 \%(3 / 197)$ \\
\hline
\end{tabular}

Abbreviations: IQR, interquartile range; HCPHPT, hypercalcemic primary hyperparathyroidism; NCPHPT, normocalcemic primary hyperparathyroidism; SPHPT, symptomatic primary hyperparathyroidism; ASPHPT, asymptomatic primary hyperparathyroidism; PHPT, primary hyperparathyroidism.

adenomas that were not removed, and 2 cases had multiple parathyroid hyperplasia which was not completely removed. After surgery, 3 cases (1.52\%) had a relapse.

\subsection{Comparison between the HCPHPT and NCPHPT Groups.}

The HCPHPT group contained 162 (82.23\%) cases, and the NCPHPT group contained $35(17.77 \%)$ cases. There was no significant difference in age and sex between the 2 groups ( $\mathrm{P}>0.05$, Table 2$)$. In the preoperative biochemical examination, the concentrations of PTH and serum calcium in the HCPHPT group were significantly higher than those in the NCPHPT group ( $\mathrm{P}<0.0001)$, but there was no significant difference in AKP and serum phosphorus between the 2 groups $(\mathrm{P}>0.05)$. Patients in the HCPHPT group were more likely to present with symptoms than patients in the NCPHPT group $(\mathrm{P}<0.05$, Table 2$)$; however, there was no significant difference in type I or II symptoms and composition between the 2 groups $(\mathrm{P}>0.05)$. Both postoperative serum calcium and phosphorus in the HCPHPT group were significantly higher than those in the NCPHPT group ( $P$ $<0.05$, Table 3 ). There was no significant difference between the 2 groups regarding the concentration of postoperative $\mathrm{PTH}$ or the diameter, type, and number of lesions. Moreover, the success rate of the operation, the postoperative recurrence rate, and the symptoms of temporary hypocalcemia were not significantly different between the groups (Table 3).

3.3. Comparison between the SPHPT and ASPHPT Groups. The SPHPT group contained $89(45.18 \%)$ cases, and the ASPHPT group contained 108 (54.82\%) cases. There was no significant difference in age and sex between the 2 groups $(\mathrm{P}$ $>0.05$, Table 4 ). In the preoperative biochemical examination, the concentrations of PTH, AKP, and calcium in the SPHPT group were significantly higher than those in the ASPHPT group $(\mathrm{P}<0.0001)$, but there was no significant difference in the serum phosphorus levels between the 2 groups $(\mathrm{P}$ $>0.05)$. The postoperative serum calcium and lesion diameter of the SPHPT group were larger than those in the ASPHPT group, and the concentrations of postoperative PTH and serum phosphorus were lower than those in the ASPHPT group $(\mathrm{P}<0.05)$ (Table 5). Concerning the pathological type of the lesion, the proportion of adenoma in the SPHPT group was significantly higher than that in the ASPHPT group, and the proportion of hyperplasia was significantly lower than that in the ASPHPT group $(\mathrm{P}<0.05)$. There was no significant difference in the number of lesions between the groups. The number of patients that underwent simultaneous thyroidectomy was significantly different between the SPHPT group (11.24\%) and the ASPHPT group (37.96\%) (P <0.0001). Operative success rate, postoperative recurrence rate, and temporary symptoms of hypocalcemia were not significantly different between the groups (Table 5).

3.4. Incidence of PHPT between 2008-2012 and 2013-2018. The number of patients with PHPT was significantly higher in group B (the last 5 years) than in group A (the first 5 years), and there was no significant difference in sex, age, and pre-operative calcium between the groups (Table 6). The concentrations of pre-operative $\mathrm{PTH}$ and AKP in group $\mathrm{B}$ were significantly lower than those in group A $(\mathrm{P}<0.05)$, while that of pre-operative serum phosphorus in group $\mathrm{B}$ was significantly higher than that in group $A(P=0.003)$. In group $A, 84.09 \%(n=37)$ of patients showed clinical symptoms which was a significantly higher proportion than that of patients with clinical symptoms in group B $(33.99 \%$, $\mathrm{n}=52)(\mathrm{P}<0.0001)$. The proportion of patients with multiple symptoms was significantly higher in group $\mathrm{A}$ than in group $\mathrm{B}(\mathrm{P}=0.007)$, and the prevalence of renal and skeletal diseases was significantly higher in group $\mathrm{A}$ than in group $\mathrm{B}(\mathrm{P}<0.001)$.

\section{Discussion}

This study examined whether there were differences between the surgical outcomes of patients with SPHPT versus ASPHPT and HCPHPT versus NCPHPT. By comparing the clinical features and surgical outcomes of the groups, we found no difference between the outcomes of surgical treatment. Moreover, the analysis of clinical features showed that PHPT combined with thyroid nodules was more common. By comparing the treatment of hyperparathyroidism during the last 10 years, the number of PHPT patients in the last 5 years was found to be significantly higher than that in the preceding 5 years, which was consistent with the overall increasing trend in the incidence of PHPT in recent years.

Our data showed that HCPHPT is the most common form of PHPT in northern China, which is consistent with other research centers in China [20]. The pathological mechanism of NCPHPT is unclear; however, there are 2 main current hypotheses. The first hypothesis is that NCPHPT is an early-stage or attenuated PHPT [21]. Another hypothesis 


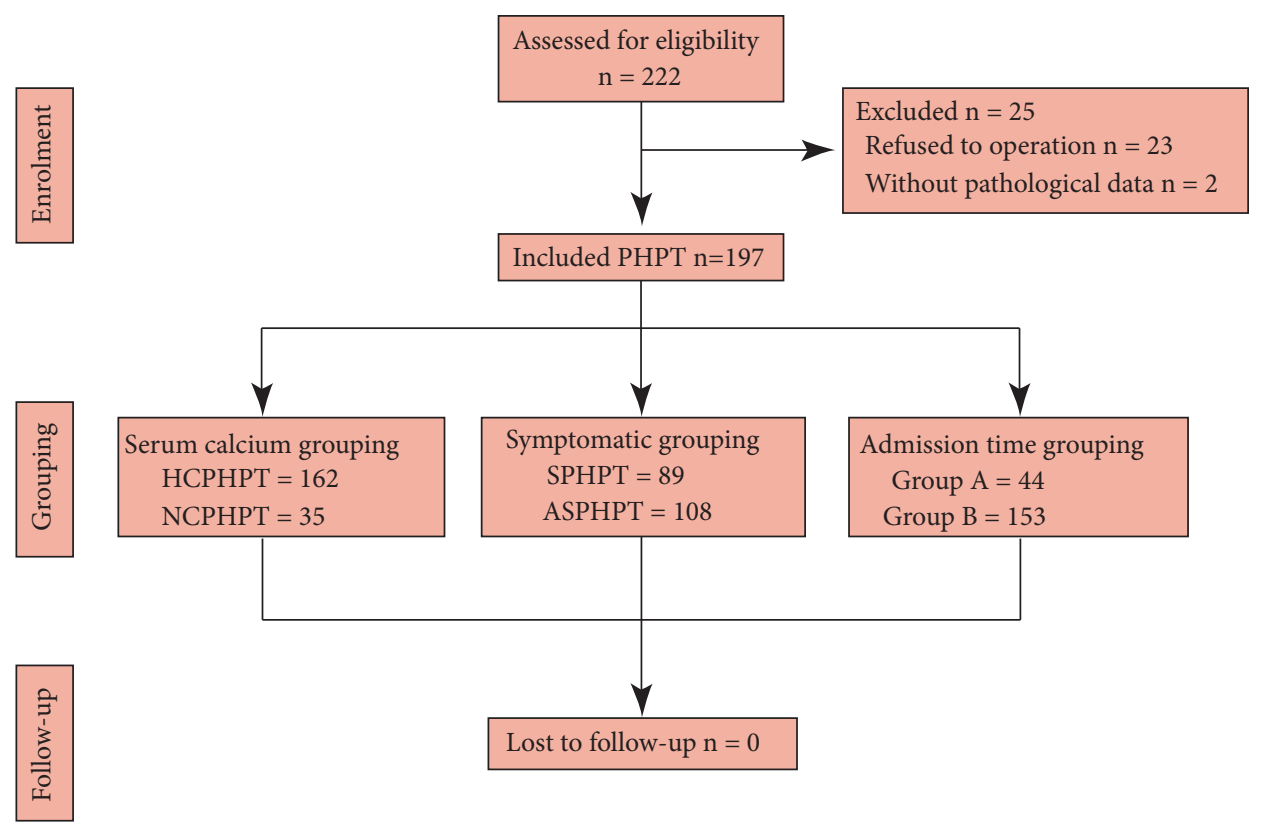

FIGURE 1: Study flow chart. Abbreviations: PHPT, primary hyperparathyroidism; HCPHPT, hypercalcemic primary hyperparathyroidism; NCPHPT, normocalcemic primary hyperparathyroidism; SPHPT, symptomatic primary hyperparathyroidism; ASPHPT, asymptomatic primary hyperparathyroidism; Group A: Patients who have been receiving treatment in 2008-2012; Group B: Patients who have been receiving treatment in 2013-2017.

TABLE 2: Comparison of preoperative data between HCPHPT group and NCPHPT group.

\begin{tabular}{|c|c|c|c|}
\hline Index & $\begin{array}{l}\text { HCPHPT group } \\
n=162\end{array}$ & $\begin{array}{l}\begin{array}{l}\text { NCPHPT group } \\
n=35\end{array}\end{array}$ & $P$ value \\
\hline Age $(y) \pm S D$ & $48.39 \pm 12.04$ & $50.54 \pm 13.94$ & 0.352 \\
\hline Sex & & & 0.632 \\
\hline male & $40(24.69 \%)$ & $10(28.57 \%)$ & \\
\hline female & $122(75.31 \%)$ & $25(71.43 \%)$ & \\
\hline Preoperative PTH $(\mathrm{uIU} / \mathrm{ml}) \pm \mathrm{SD}$ & $781.65 \pm 799.25$ & $347.38 \pm 372.56$ & $<0.0001$ \\
\hline Preoperative AKP $(\mathrm{U} / \mathrm{L}) \pm \mathrm{SD}$ & $295.37 \pm 365.35$ & $174.99 \pm 269.13$ & 0.067 \\
\hline Preoperative $\mathrm{Ca}(\mathrm{mmol} / \mathrm{L}) \pm \mathrm{SD}$ & $3.06 \pm 0.38$ & $2.37 \pm 0.35$ & $<0.0001$ \\
\hline Preoperative $\mathrm{P}(\mathrm{mmol} / \mathrm{L}) \pm \mathrm{SD}$ & $2.64 \pm 15.25$ & $0.93 \pm 0.21$ & 0.507 \\
\hline Patients with symptom & & & 0.029 \\
\hline yes & $48.77 \%(79 / 162)$ & $28.57 \%(10 / 35)$ & \\
\hline no & $51.23 \%(83 / 162)$ & $71.43 \%(25 / 35)$ & \\
\hline Symptom type I & & & 0.179 \\
\hline Single symptoms & $54.43 \%(43 / 79)$ & $80.00 \%(8 / 10)$ & \\
\hline Multiple symptoms & $45.57 \%(36 / 79)$ & $20.00 \%(2 / 10)$ & \\
\hline Symptom type II & & & 0.540 \\
\hline nephrolithiasis & $24.69 \%(40 / 162)$ & $8.57 \%(3 / 35)$ & 0.023 \\
\hline osseous lesion & $24.07 \%(39 / 162)$ & $17.14 \%(6 / 35)$ & 0.506 \\
\hline gastrointestinal symptoms & $8.64 \%(14 / 162)$ & $5.71 \%(2 / 35)$ & 0.742 \\
\hline others & $15.43 \%(25 / 162)$ & $2.86 \%(1 / 35)$ & 0.053 \\
\hline
\end{tabular}

Abbreviations: HCPHPT, hypercalcemic primary hyperparathyroidism; NCPHPT, normocalcemic primary hyperparathyroidism; PTH, parathyroid hormone; AKP, alkaline phosphatase. 
TABLE 3: Comparison of postoperative data between HCPHPT group and NCPHPT group.

\begin{tabular}{lccc}
\hline Index & HCPHPT group & NCPHPT group \\
$\mathrm{n}=162$ & 35 & $P$ value \\
\hline Postoperative PTH $(\mathrm{uIU} / \mathrm{ml}) \pm \mathrm{SD}$ & $50.29 \pm 160.25$ & $44.76 \pm 40.58$ & 0.840 \\
Postoperative $\mathrm{Ca}(\mathrm{mmol} / \mathrm{L}) \pm \mathrm{SD}$ & $2.39 \pm 0.33$ & $2.19 \pm 0.18$ & $1.17 \pm 0.25$ \\
Postoperative P $(\mathrm{mmol} / \mathrm{L}) \pm \mathrm{SD}$ & $0.86 \pm 0.27$ & $1.97 \pm 0.82$ & \\
Lesion diameter $(\mathrm{cm})^{\mathrm{a}}$ & $2.29 \pm 1.23$ & & \\
Pathological type & & $77.14 \%(27 / 35)$ & 0.0001 \\
$\quad$ Parathyroid adenoma & $82.72 \%(134 / 162)$ & $22.86 \%(8 / 35)$ \\
$\quad$ Parathyroid hyperplasia & $13.58 \%(22 / 162)$ & $0.00 \%(0 / 35)$ \\
$\quad$ Parathyroid carcinoma & $1.23 \%(2 / 162)$ & $0.00 \%(0 / 35)$ \\
$\quad 2.47 \%(4 / 162)$ & $91.43 \%(32 / 35)$ \\
Parathyroid adenoma with hyperplasia & $97.53 \%(158 / 162)$ & $0.00 \%(0 / 35)$ \\
Recurre rate of PHPT & $1.85 \%(3 / 162)$ & $20.00 \%(7 / 35)$ \\
Incidence of temporary hypocalcemia & $13.58 \%(22 / 162)$ & 0.512 \\
\hline
\end{tabular}

a. For multiple lesion tissues, the diameter of the largest lesion tissue was calculated.

Abbreviations: HCPHPT, hypercalcemic primary hyperparathyroidism; NCPHPT, normocalcemic primary hyperparathyroidism; PTH, parathyroid hormone; PHPT, primary hyperparathyroidism.

TABLE 4: Comparison of preoperative data between SPHPT group and ASPHPT group.

\begin{tabular}{|c|c|c|c|}
\hline Index & $\begin{array}{c}\begin{array}{c}\text { SPHPT group } \\
\mathrm{n}=89\end{array}\end{array}$ & $\begin{array}{l}\text { ASPHPT group } \\
n=108\end{array}$ & $P$ value \\
\hline Age $(y) \pm S D$ & $47.93 \pm 12.29$ & $49.54 \pm 12.33$ & 0.394 \\
\hline Sex & & & 0.262 \\
\hline male & $26(29.21 \%)$ & $24(22.22 \%)$ & \\
\hline female & $63(70.79 \%)$ & $84(77.78 \%)$ & \\
\hline Preoperative PTH $(\mathrm{uIU} / \mathrm{ml}) \pm \mathrm{SD}$ & $\begin{array}{c}1110.69 \pm \\
1058.09\end{array}$ & $435.98 \pm 396.14$ & $<0.0001$ \\
\hline Preoperative AKP $(\mathrm{U} / \mathrm{L}) \pm \mathrm{SD}$ & $353.67 \pm 418.62$ & $190.25 \pm 201.31$ & $<0.0001$ \\
\hline Preoperative $\mathrm{Ca}(\mathrm{mmol} / \mathrm{L}) \pm \mathrm{SD}$ & $3.12 \pm 0.51$ & $2.80 \pm 0.38$ & $<0.0001$ \\
\hline Preoperative $\mathrm{P}(\mathrm{mmol} / \mathrm{L}) \pm \mathrm{SD}$ & $0.94 \pm 0.42$ & $0.96 \pm 0.32$ & 0.702 \\
\hline \multicolumn{4}{|l|}{ Symptom type I } \\
\hline Single symptoms & $57.30 \%(51 / 89)$ & - & \\
\hline Multiple symptoms & $42.70 \%(38 / 89)$ & - & \\
\hline \multicolumn{4}{|l|}{ Symptom type II } \\
\hline nephrolithiasis & $48.31 \%(43 / 89)$ & - & \\
\hline osseous lesion & $50.56 \%(45 / 89)$ & - & \\
\hline gastrointestinal symptoms & $17.98 \%(16 / 89)$ & - & \\
\hline others & $29.21 \%(26 / 89)$ & - & \\
\hline
\end{tabular}

Abbreviations: SPHPT, symptomatic primary hyperparathyroidism; ASPHPT, asymptomatic primary hyperparathyroidism; PTH, parathyroid hormone; AKP, alkaline phosphatase.

is that some of the tissues of patients with NCPHPT may be resistant to PTH [22]. Compared with patients with normal blood calcium, the surgical outcome of patients with elevated blood calcium was not significantly different. However, the incidence of clinical symptoms was higher in patients with NCPHPT than in patients with HCPHPT, but there was no statistical difference in the composition of the symptoms. Although the timing of surgical treatment for NCPHPT patients is somewhat controversial, studies have shown that surgery is beneficial in preventing a decrease in bone density [23].

In this study, the proportion of SPHPT patients was comparable to that of ASPHPT patients, but it was significantly lower than that reported in developed countries (70\%-81.8\%) [24-26]. Preoperative PTH, AKP, and calcium of the SPHPT patients were significantly higher than those of the asymptomatic group. In addition, patients with clinical symptoms were more likely to be diagnosed and have 
TABLE 5: Comparison of postoperative data between SPHPT group and ASPHPT group.

\begin{tabular}{|c|c|c|c|}
\hline Index & $\begin{array}{c}\text { SPHPT group } \\
\mathrm{n}=89\end{array}$ & $\begin{array}{c}\text { ASPHPT group } \\
n=108\end{array}$ & $P$ value \\
\hline Postoperative $\mathrm{PTH}(\mathrm{uIU} / \mathrm{ml}) \pm \mathrm{SD}$ & $31.94 \pm 47.55$ & $63.48 \pm 192.00$ & 0.031 \\
\hline Postoperative $\mathrm{Ca}(\mathrm{mmol} / \mathrm{L}) \pm \mathrm{SD}$ & $2.42 \pm 0.39$ & $2.31 \pm 0.23$ & $<0.0001$ \\
\hline Postoperative $\mathrm{P}(\mathrm{mmol} / \mathrm{L}) \pm \mathrm{SD}$ & $0.82 \pm 0.26$ & $0.99 \pm 0.30$ & $<0.0001$ \\
\hline Lesion diameter $(\mathrm{cm})^{\mathrm{a}}$ & $2.43 \pm 1.17$ & $2.07 \pm 1.22$ & 0.034 \\
\hline Pathological type & & & 0.053 \\
\hline Parathyroid adenoma & $88.76 \%(79 / 89)$ & $75.93 \%(82 / 108)$ & 0.026 \\
\hline Parathyroid hyperplasia & $8.99 \%(8 / 89)$ & $20.37 \%(22 / 108)$ & 0.029 \\
\hline Parathyroid carcinoma & $0.00 \%(0 / 89)$ & $1.85 \%(2 / 108)$ & 0.502 \\
\hline Parathyroid adenoma with hyperplasia & $2.25 \%(2 / 89)$ & $1.85 \%(2 / 108)$ & $>0.99$ \\
\hline Combined thyroidectomy & & & $<0.0001$ \\
\hline yes & $11.24 \%(10 / 89)$ & $37.96 \%(41 / 108)$ & \\
\hline no & $88.76 \%(79 / 89)$ & $62.04 \%(67 / 108)$ & \\
\hline Cure rate of PHPT & $96.63 \%(86 / 89)$ & $96.30 \%(104 / 108)$ & $>0.99$ \\
\hline Recurrence rate of PHPT & $1.12 \%(1 / 89)$ & $1.85 \%(2 / 108)$ & $>0.99$ \\
\hline Incidence of temporary hypocalcemia & $13.48 \%(12 / 89)$ & $15.74 \%(17 / 108)$ & 0.691 \\
\hline
\end{tabular}

a. For multiple lesion tissues, the diameter of the largest lesion tissue was calculated.

Abbreviations: SPHPT, symptomatic primary hyperparathyroidism; ASPHPT, asymptomatic primary hyperparathyroidism; PTH, parathyroid hormone; PHPT, primary hyperparathyroidism.

TABLE 6: Clinical data of group A and group B.

\begin{tabular}{|c|c|c|c|}
\hline Index & $\begin{array}{c}\text { Group A } \\
\mathrm{n}=44\end{array}$ & $\begin{array}{c}\text { Group B } \\
n=153\end{array}$ & $P$ value \\
\hline PHPT & $22.34 \%(44 / 197)$ & $77.66 \%(153 / 197)$ & \\
\hline Age $(y) \pm S D$ & $46.00 \pm 12.30$ & $49.43 \pm 12.35$ & 0.106 \\
\hline Sex & & & 0.948 \\
\hline male & $25.00 \%(11 / 44)$ & $25.49 \%(39 / 153)$ & \\
\hline female & $75.00 \%(33 / 44)$ & $74.51 \%(114 / 153)$ & \\
\hline Preoperative $\mathrm{PTH}$ & $1025.54 \pm 887.69$ & $657.10 \pm 806.75$ & 0.01 \\
\hline Preoperative AKP & $456.45 \pm 551.29$ & $221.70 \pm 248.84$ & 0.008 \\
\hline Preoperative $\mathrm{Ca}$ & $3.01 \pm 0.40$ & $2.93 \pm 0.48$ & 0.297 \\
\hline Preoperative P & $0.80 \pm 0.24$ & $0.95 \pm 0.38$ & 0.003 \\
\hline SPHPT & $84.09 \%(37 / 44)$ & $33.99 \%(52 / 153)$ & $<0.0001$ \\
\hline Symptom type I & & & 0.007 \\
\hline Single symptoms & $40.54 \%(15 / 37)$ & $69.23 \%(36 / 52)$ & \\
\hline Multiple symptoms & $59.46 \%(22 / 37)$ & $30.77 \%(16 / 52)$ & \\
\hline \multicolumn{4}{|l|}{ Symptom type II } \\
\hline nephrolithiasis & $56.82 \%(25 / 44)$ & $11.76 \%(18 / 153)$ & $<0.0001$ \\
\hline osseous lesion & $52.27 \%(23 / 44)$ & $14.38 \%(22 / 153)$ & $<0.0001$ \\
\hline gastrointestinal symptoms & $9.09 \%(4 / 44)$ & $7.84 \%(12 / 153)$ & 0.759 \\
\hline others & $18.18 \%(8 / 44)$ & $11.76 \%(18 / 153)$ & 0.268 \\
\hline
\end{tabular}

Group A: Patients who have been treated for 2008-2012; Group B: Patients who have been treated for 2013-2017.

Abbreviations: PHPT, primary hyperparathyroidism; PTH, parathyroid hormone; AKP, alkaline phosphatase.

greater opportunities for surgical treatment. In terms of surgical outcomes, there was no statistical difference between symptomatic and asymptomatic patients. However, surgery can significantly improve the postoperative quality of life of patients, especially regarding neurocognition, sleep, and blood pressure [27] and also improve bone fiber results and increase bone strength [28]. Therefore, surgery was relatively large for patients with PHPT, especially those with SPHPT.

In this study, 39.09\% of PHPT patients had concurrent thyroid nodules. PHPT combined with thyroid nodules has 
attracted much attention in recent years, especially when combined with non-medullary thyroid carcinoma. The incidence of PHPT combined with thyroid nodules has increased threefold [29, 30]. Neslihan et al. [31] reported that $66.7 \%$ of PHPT patients also had thyroid nodules; the postoperative pathological results showed that $79.2 \%$ of the thyroid nodules were benign thyroid diseases, and $20.8 \%$ were papillary thyroid carcinoma. Recent studies show that a total of $60 \%$ of patients with PHPT have thyroid disease, while almost one-third of patients are not aware of this disease before the diagnosis of PHPT [32]. The incidence of PHPT coupled with either thyroid nodules or thyroid cancer is increasing, which makes diagnosis and treatment more complex. Among the 51 cases with thyroid nodules complicated with PHPT, $43.14 \%$ were combined with papillary thyroid carcinoma. In the past, the proportion of PHPT cases with thyroid cancer was $10.87 \%-12.9 \%[33,34]$. Therefore, it is necessary to perform surgical treatment for PHPT combined with thyroid disease when the pathological hyperthyroidism is removed by surgery.

In this study, the proportion of female patients was significantly higher than that of male patients, accounting for $74.62 \%$ of the total patients. This difference has been observed in multiple regions and populations. In a study of 464 PHPT patients in India, women accounted for $70.47 \%$ of all patients [35], and in a single-center study of 300 PHPT patients in Rhode Island Hospital, women accounted for $74 \%$ of all patients [36]. PHPT is more common in women than in men, with a 3:1 sex ratio [37]. According to an epidemiological survey using big data, the prevalence of PHPT in the United States has been estimated at 23 cases per 10,000 women and 8.5 cases per 10,000 men, with an incidence of 65.5 cases per 100,000 person-years in women and 24.7 cases per 100,000 person-years in men [38]. The specific reasons for these differences remain unexplained. In this study, the average age of PHPT patients was lower than that reported in previous studies [36, 38], especially in developed regions; however, it was higher than the average age ( $41 \pm 14$ years) reported in the previous Indian study [35], which may be related to the regional economy and healthcare of residents as well as other factors.

The limitations of this study are as follows. First, this was a single-center retrospective study with bias in patient selection. Second, there was insufficient power to reliably evaluate the difference in cure rate between the normocalcemic and hypercalcemic groups. However, considering the proportion of patients in the present study and assuming the power was 0.9, 737 patients would have to be included in the HCPHPT group and 160 in the NCPHPT group to make the difference in the cure rate of $6.1 \%$ statistically significant.

\section{Conclusion}

Parathyroidectomy is a safe and effective treatment for HCPHPT and NCPHPT. Although patients with SPHPT are different from those with ASPHPT regarding some indicators, the differences do not affect the results of surgical treatment. We also found that the incidence of PHPT in northern China is increasing. Thyroid surgery should be performed for PHPT patients with thyroid nodules. In future studies, the hypercalcemic group could be further divided into subgroups according to the critical blood calcium value of $3.49 \mathrm{mmol} / \mathrm{L}$ to compare differences in surgical treatment outcome between PHPT patients with normal blood calcium, hypercalcemia, and severe hypercalcemia.

\section{Data Availability}

The data used to support the findings of this study are available from the corresponding author upon request.

\section{Ethical Approval}

This study was approved by the ethics committee of First Affiliated Hospital of Harbin Medical University. All procedures performed in studies involving human participants were in accordance with the ethical standards of the institutional and/or national research committee and with the 1964 Helsinki Declaration and its later amendments or comparable ethical standards.

\section{Consent}

Informed consent was obtained from all individual participants included in the study.

\section{Conflicts of Interest}

The authors declare that they have no conflicts of interest.

\section{References}

[1] L. J. Melton, "Epidemiology of primary hyperparathyroidism," Journal of Bone and Mineral Research, vol. 17, Suppl 2, pp. N12N17, 2002.

[2] C. Marcocci and F. Saponaro, "Epidemiology, pathogenesis of primary hyperparathyroidism: current data," Annales d'Endocrinologie, vol. 76, no. 2, pp. 113-115, 2015.

[3] A. Abood and P. Vestergaard, "Increasing incidence of primary hyperparathyroidism in Denmark," Danish Medical Journal, vol. 60, article A4567, 2013.

[4] M. L. Griebeler, A. E. Kearns, E. Ryu, M. A. Hathcock, L. J. Melton, and R. A. Wermers, "Secular trends in the incidence of primary hyperparathyroidism over five decades (1965-2010)," Bone, vol. 73, pp. 1-7, 2015.

[5] E. Lundgren, E. G. Hagström, J. Lundin et al., "Primary hyperparathyroidism revisited in menopausal women with serum calcium in the upper normal range at population-based screening 8 years ago," World Journal of Surgery, vol. 26, no. 8, pp. 931-936, 2002.

[6] B. L. Clarke, "Epidemiology of primary hyperparathyroidism," Journal of Clinical Densitometry, vol. 16, no. 1, pp. 8-13, 2013.

[7] S. Pallan, M. O. Rahman, and A. A. Khan, "Diagnosis and management of primary hyperparathyroidism," BMJ, vol. 344, article e1013, 2012.

[8] J. P. Bilezikian and S. J. Silverberg, "Clinical practice. Asymptomatic primary hyperparathyroidism," The New England Journal of Medicine, vol. 350, pp. 1746-1751, 2004. 
[9] S. M. Wilhelm, T. S. Wang, D. T. Ruan et al., "The American association of endocrine surgeons guidelines for definitive management of primary hyperparathyroidism," JAMA Surgery, vol. 151, no. 10, pp. 959-968, 2016.

[10] J. P. Bilezikian, L. Bandeira, A. Khan, and N. E. Cusano, "Hyperparathyroidism," The Lancet, vol. 391, no. 10116, pp. 168178, 2018.

[11] M. Parisien, S. J. Silverberg, E. Shane, D. W. Dempster, and J. P. Bilezikian, "Bone disease in primary hyperparathyroidism," Endocrinology and Metabolism Clinics of North America, vol. 19, no. 1, pp. 19-34, 1990.

[12] L. A. Ranjan, S. Vijaya, J. Varsha, B. Tushar, and P. S. Menon, "Samir SN: renal manifestations of primary hyperparathyroidism," Indian Journal of Endocrinology Metabolism, vol. 16, pp. 258-262, 2012.

[13] S. J. Silverberg, B. L. Clarke, M. Peacock et al., "Current issues in the presentation of asymptomatic primary hyperparathyroidism: proceedings of the fourth International workshop," The Journal of Clinical Endocrinology \& Metabolism, vol. 99, no. 10, pp. 3580-3594, 2014.

[14] A. Trombetti, E. R. Christ, C. Henzen et al., "Clinical presentation and management of patients with primary hyperparathyroidism of the Swiss Primary Hyperparathyroidism Cohort: A focus on neuro-behavioral and cognitive symptoms," Journal of Endocrinological Investigation, vol. 39, no. 5, pp. 567-576, 2016.

[15] B. Abboud, R. Daher, and J. Boujaoude, "Digestive manifestations of parathyroid disorders," World Journal of Gastroenterology, vol. 17, no. 36, pp. 4063-4066, 2011.

[16] D. Han, S. Trooskin, and X. Wang, "Prevalence of cardiovascular risk factors in male and female patients with primary hyperparathyroidism," Journal of Endocrinological Investigation, vol. 35, pp. 548-552, 2012.

[17] M. D. Walker, D. J. McMahon, W. B. Inabnet et al., "Neuropsychological features in primary hyperparathyroidism: a prospective study," The Journal of Clinical Endocrinology \& Metabolism, vol. 94, no. 6, pp. 1951-1958, 2009.

[18] M. D. Walker, M. Rubin, and S. J. Silverberg, "Nontraditional manifestations of primary hyperparathyroidism," Journal of Clinical Densitometry, vol. 16, no. 1, pp. 40-47, 2013.

[19] S. J. Silverberg, M. D. Walker, and J. P. Bilezikian, "Asymptomatic Primary Hyperparathyroidism," Journal of Clinical Densitometry, vol. 16, no. 1, pp. 14-21, 2013.

[20] L. Zhao, J. Liu, X. He et al., "The changing clinical patterns of primary hyperparathyroidism in chinese patients: data from 2000 to 2010 in a single clinical center," The Journal of Clinical Endocrinology \& Metabolism, vol. 98, no. 2, pp. 721-728, 2013.

[21] S. J. Silverberg and J. P. Bilezikian, “"Incipient” primary hyperparathyroidism: a "forme fruste" of an old disease," The Journal of Clinical Endocrinology \& Metabolism, vol. 88, no. 11, pp. 53485352, 2003.

[22] G. Maruani, A. Hertig, M. Paillard, and P. Houillier, "Normocalcemic primary hyperparathyroidism: evidence for a generalized target-tissue resistance to parathyroid hormone," The Journal of Clinical Endocrinology \& Metabolism, vol. 88, no. 10, pp. 46414648, 2003.

[23] E. Koumakis, J.-C. Souberbielle, E. Sarfati et al., "Bone mineral density evolution after successful parathyroidectomy in patients with normocalcemic primary hyperparathyroidism," The Journal of Clinical Endocrinology \& Metabolism, vol. 98, no. 8, pp. 3213-3220, 2013.
[24] C. Eufrazino, A. Veras, and F. Bandeira, "Epidemiology of primary hyperparathyroidism and its non-classical manifestations in the city of Recife, Brazil," Clinical Medicine Insights: Endocrinology and Diabetes, vol. 6, pp. 69-74, 2013.

[25] M. Muñoz Torres, E. Jodar Gimeno, R. Reyes Garcia et al., "Results from a national survey on the management of primary hyperparathyroidism," Journal of Endocrinological Investigation, vol. 35, no. 11, pp. 957-963, 2012.

[26] W. D. Fraser, "Hyperparathyroidism," The Lancet, vol. 374, no. 9684, pp. 145-158, 2009.

[27] S. Storvall, E. M. Ryhänen, I. Heiskanen, H. Sintonen, R. P. Roine, and C. Schalin-Jäntti, "Surgery significantly improves neurocognition, sleep, and blood pressure in primary hyperparathyroidism: a 3-year prospective follow-up study, Hormone and Metabolic Research, vol. 49, no. 10, pp. 772-777, 2017.

[28] N. E. Cusano, M. R. Rubin, B. C. Silva et al., "Skeletal microstructure and estimated bone strength improve following parathyroidectomy in primary hyperparathyroidism," The Journal of Clinical Endocrinology \& Metabolism, vol. 103, no. 1, pp. 196-205, 2018.

[29] S. Y. Morita, H. Somervell, C. B. Umbricht, A. P. B. Dackiw, and M. A. Zeiger, "Evaluation for concomitant thyroid nodules and primary hyperparathyroidism in patients undergoing parathyroidectomy or thyroidectomy," Surgery, vol. 144, no. 6, pp. 862$867,2008$.

[30] B. Wagner, S. Begic-Karup, W. Raber, B. Schneider, W. Waldhäusl, and H. Vierhapper, "Prevalence of primary hyperparathyroidism in 13387 patients with thyroid diseases, newly diagnosed by screening of serum calcium," Experimental and Clinical Endocrinology \& Diabetes, vol. 107, no. 7, pp. 457-461, 1999.

[31] N. Cuhaci, D. Ozdemir, B. Polat et al., "Concomitant thyroid lesions in patients with primary hyperparathyroidism," Asian Journal of Surgery, vol. 40, no. 5, pp. 338-344, 2017.

[32] A. Latina, E. Castellano, F. Cesario, A. Boriano, R. Attanasio, and G. Borretta, "Unknown and already known thyroid abnormalities in primary hyperparathyroidism," Endocrine Practice, vol. 24, no. 7, pp. 628-633, 2018.

[33] K. Kutlutürk, E. Otan, M. A. Yagci, S. Usta, C. Aydin, and B. Ünal, "Thyroid pathologies accompanying primary hyperparathyroidism: A high rate of papillary thyroid microcarcinoma," Turkish Journal of Trauma and Emergency Surgery, vol. 30, no. 3, pp. 125-128, 2014.

[34] B. Simsek, C. E. Guldoğan, S. Ozden, B. Saylam, S. M. Karabeyoglu, and M. Tez, "Concomitant thyroid cancer in patients with primary hyperparathyroidism in an endemic goitre region," Annali Italiani Di Chirurgia, vol. 88, no. 1, pp. 15-19, 2017.

[35] S. K. Bhadada, A. K. Arya, S. Mukhopadhyay et al., "Primary hyperparathyroidism: insights from the Indian PHPT registry," Journal of Bone and Mineral Metabolism, vol. 36, no. 2, pp. 238245, 2018.

[36] P. J. Mazzaglia, E. Berber, A. Kovach, M. Milas, C. Esselstyn, and A. E. Siperstein, "The changing presentation of hyperparathyroidism over 3 decades," JAMA Surgery, vol. 143, no. 3, pp. 260266, 2008.

[37] G. Gasparri, "Updates in primary hyperparathyroidism," Updates in Surgery, vol. 69, no. 2, pp. 217-223, 2017.

[38] M. W. Yeh, P. H. G. Ituarte, H. C. Zhou et al., "Incidence and prevalence of primary hyperparathyroidism in a racially mixed population," The Journal of Clinical Endocrinology \& Metabolism, vol. 98, no. 3, pp. 1122-1129, 2013. 


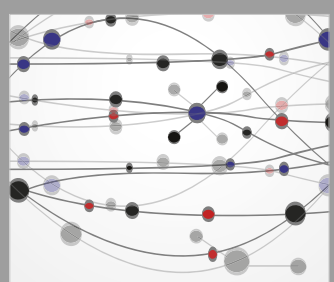

The Scientific World Journal
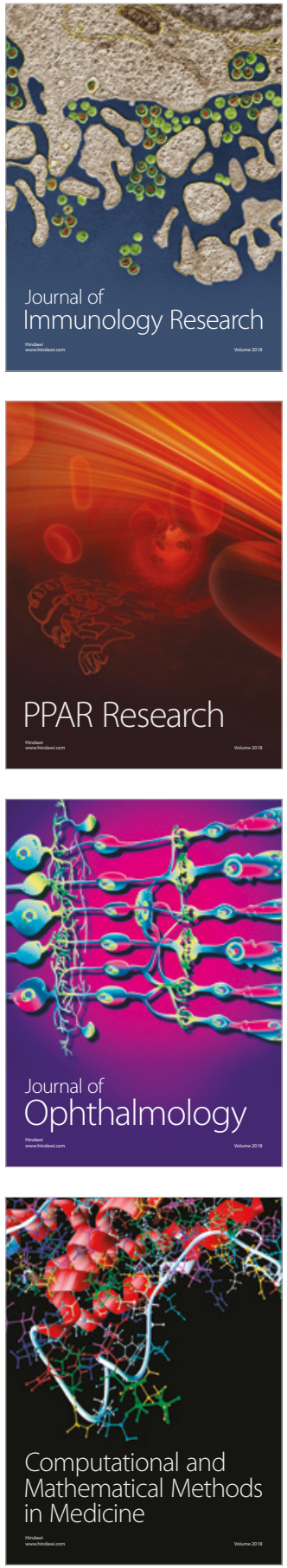

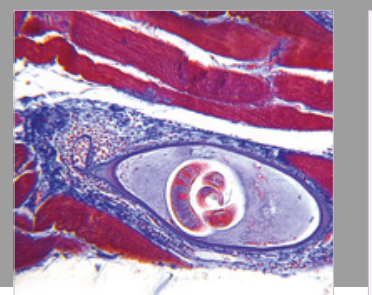

Gastroenterology Research and Practice

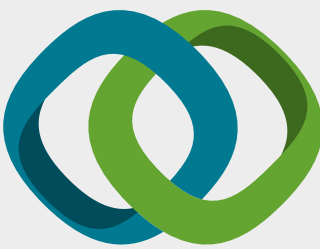

\section{Hindawi}

Submit your manuscripts at

www.hindawi.com
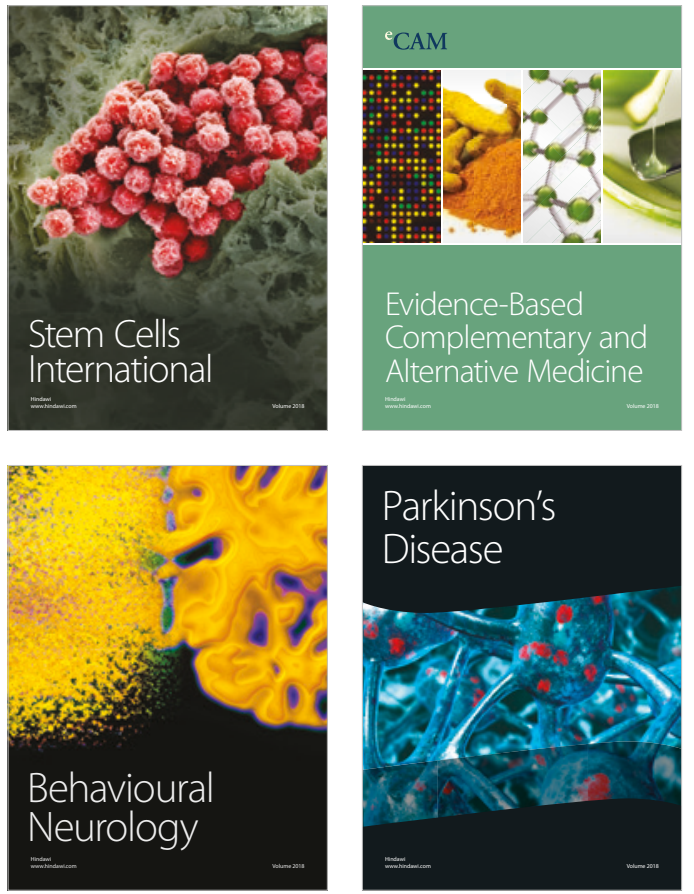

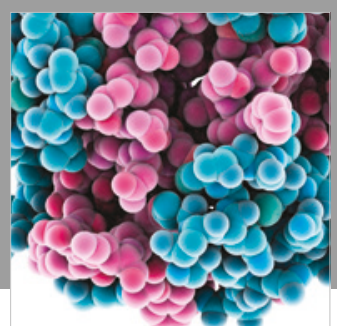

ournal of

Diabetes Research

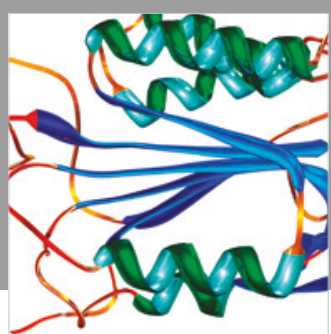

Disease Markers
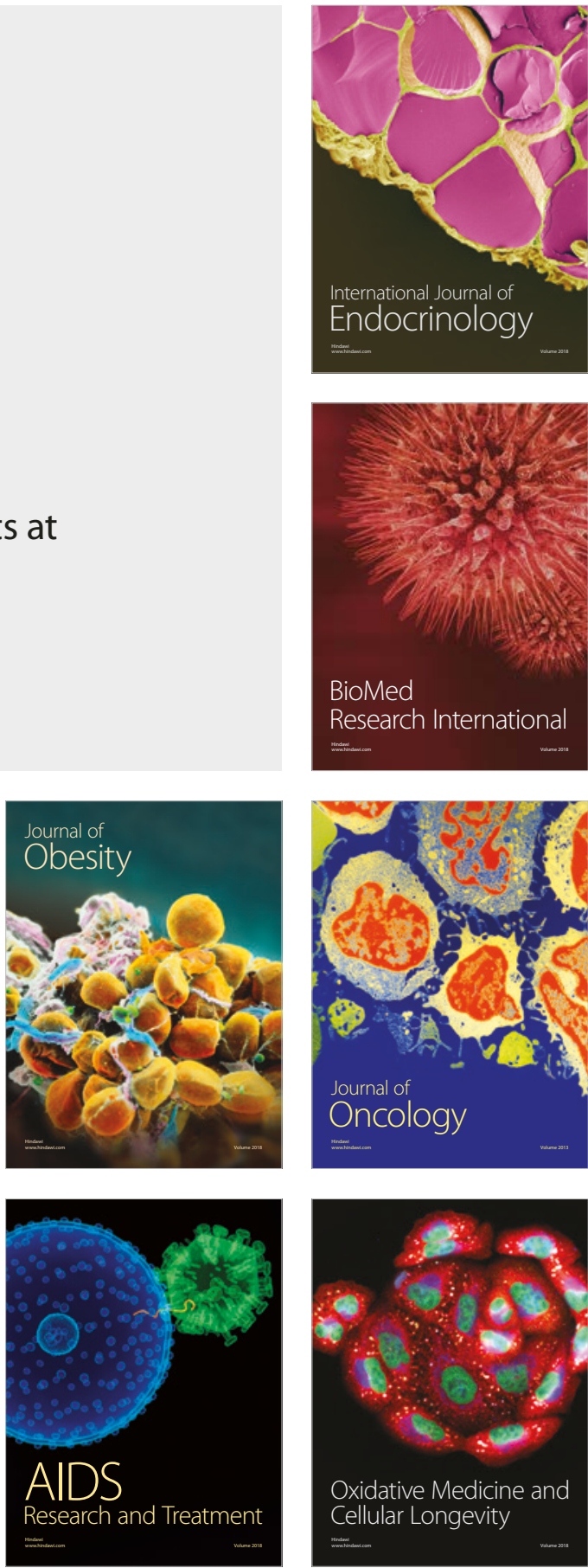